\title{
El ocaso comunista de Praga en las arquitecturas de la serie de televisión The Sleepers (Ivan Zachariáš, HBO, 2019)
}

\section{The communist twilight of Prague in the architectures of TV series The Sleepers (Ivan Zachariáš, HBO, 2019)}

\author{
Adolfo de Mingo Lorente \\ Universidad de Castilla-La Mancha, España \\ Adolfo.deMingo@uclm.es \\ https://orcid.org/0000-0002-9097-1155
}

\begin{abstract}
Resumen:
El cineasta checo Ivan Zachariáš ofrece en The Sleepers una compleja trama de espías durante las semanas previas a la Revolución de Terciopelo, que puso fin a cuatro décadas de comunismo en Checoslovaquia. Las localizaciones de esta serie de TV despersonalizan la Praga monumental gótica y barroca característica de otras producciones audiovisuales para recoger un interesante catálogo de arquitecturas racionalistas, como el edificio Dům Radost (Karel Honzík y Josef Havlíček) - netamente influido por Le Corbusier-, la sede de la organización deportiva Sokol (František Marek, Václav Vejrych y Jaroslav Kabeš) o el Krematorium Strašnice (Alois Mezera). Estos escenarios, que permiten recrear desde espacios diplomáticos hasta las oficinas de la policía política checoslovaca (ŠtB), recorren también la Praga historicista de Václav Roštlapil o la arquitectura socialista de František Jeřábek, responsable del Hotel International. Una nueva mirada cinematográfica, en suma, a una de las ciudades más arquitectónicamente diversas de Europa.
\end{abstract}

\begin{abstract}
:
Czech filmmaker Ivan Zachariáš offers a complex spy plot in The Sleepers in the previous weeks to the Velvet Revolution, which ended four decades of communism in Czechoslovakia. The film locations of this TV serie depersonalize the monumental Gothic and Baroque Prague of another audiovisual productions to collect an interesting catalog of rationalist architecture, as the building Dům Radost (Karel Honzík y Josef Havlíček) clearly influenced by Le Corbusier-, the headquarters of the sport organization Sokol (František Marek, Václav Vejrych y Jaroslav Kabeš) or the Strašnice Crematorium (Alois Mezera). These scenarios, which make possible to recreate from diplomatic spaces to the offices of the Czechoslovak political police (ك̌tB), also visit historicist Prague of Václav Roštlapil or the socialist architecture of František Jeřábek, architect for the International Hotel. A new cinematographic view, definitely, to one of the most architecturally diverse cities in Europe.
\end{abstract}

\section{Palabras clave:}

Arquitectura racionalista; comunismo; República Checa; Revolución de Terciopelo; localizaciones cinematográficas.

Keywords:

Rationalist architecture; Communism; Czech Republic; Velvet Revolution; Filming locations. 


\section{Introducción}

Son varios los motivos que han convertido a Praga en un privilegiado escenario cinematográfico. La elegante semántica centroeuropea de sus arquitecturas barrocas, su proximidad a la históricamente poderosa industria alemana y la apuesta por modernas instalaciones, como los estudios Barrandov -de los mayores de Europa-, están entre ellos, planteando una relación que se remonta hasta los propios orígenes del cine, con ejemplos tan conocidos como El estudiante de Praga (Der student von Prag, Stellan Rye y Paul Wegener, 1913).

No es de extrañar, por tanto, que la capital de la actual República Checa esté presente en distintas publicaciones dedicadas a explorar las relaciones entre el cine y la idea de ciudad, como la coordinada en 2013 por Gloria Camarero, profesora de la Universidad Carlos III, donde el capítulo correspondiente era abordado por el periodista y crítico Paolo de Vita. Ese mismo año, la historiadora del cine Marcelline Block dedicó a Praga uno de los volúmenes de su serie sobre localizaciones emblemáticas de distintas ciudades, tales como París, Boston o Las Vegas.

La enorme plasticidad de sus arquitecturas, desde el gótico civil hasta el realismo socialista de mediados del siglo XX, pasando por el neobarroco de arquitectos como Václav Roštlapil (1856-1931) o el racionalismo de Oldřich Tyl (1884-1939), está presente no solo en la propia identidad de Praga como sujeto cinematográfico, sino también en los abundantes ejemplos de ciudades que han sido recreadas a partir de la capital checa. La Ciudad Vieja (Staré Město) ha sido tanto la Viena dieciochesca de Amadeus (Milos Forman, 1984) como la polaca Lublin de Yentl (Barbra Streisand, 1983) y el Moscú comunista de la reciente El niño 44 (Child 44, Daniel Espinosa, 2015). A estos ejemplos y a otros muchos es posible añadir visiones imaginarias, como la del gueto de Praga en El Golem (Der Golem, wie er in die Welt kam, Carl Boese y Paul Wegener, 1920), más ambientaciones como las realizadas en los estudios Barrandov, estudiados por Hejlícková (1989), donde llegó a construirse toda una réplica de la Capilla Sixtina y los apartamentos papales para la serie Los Borgia (Borgia: Faith and Fear, Oliver Hirschbiegel, 20112014).

Frente a esta Praga monumental resultan mucho menos abundantes -al menos, fuera de la República Checa- las visiones que renuncian a una dimensión historicista o pintoresca de sus arquitecturas. Este afán por despersonalizar el pasado 
está especialmente presente en varias producciones que, desde la caída del régimen comunista tras la Revolución de Terciopelo, han dirigido la mirada a la antigua Checoslovaquia socialista. Veronika Pehe (Academia de las Ciencias de la República Checa) ha manifestado recientemente el contraste entre dos series tan populares como la colorida Tell (Vyprávěj, Biser Arichtev, 2009-2013) y la mucho más cruda Burning Bush (Hořící keř, 2013), basada en la autoinmolación del estudiante Jan Palach durante las protestas por el fin de la Primavera de Praga. Esta miniserie de tres capítulos, filmada por la prestigiosa directora polaca Agnieszka Holland, fue la primera gran apuesta de HBO por el pasado político checo. La segunda fue The Sleepers (Bez vědomí, Ivan Zachariáš, HBO, 2019). En ambas participó la actriz de origen eslovaco Tatiana Pauhofová.

Forman parte de este contexto no precisamente complaciente con el pasado socialista de la República Checa ejemplos tan destacados como Kolja (Jan Sverák, 1996) -que llegó a obtener el Oscar a la Mejor Película de Habla no inglesa- o Pouta (Radim Špaček, 2010), cuyo protagonista era un atormentado miembro de la policía política checoslovaca, la ŠtB (Státní bezpečnost), durante la década de los años ochenta. Esta última, aclamada por la crítica y considerada una de las mejores películas checas del nuevo milenio, comparte elementos de ambientación y puesta en escena con The Sleepers en lo que atañe a la representación de la decadencia del aparato político - no la exaltación de la Praga socialista a través de sus palacios de congresos o inmensas instalaciones deportivas, sino la escasez material de sus hospitales o los baratos e impersonales muebles de formica de sus comisarías- en los albores de la Revolución de Terciopelo. La dicotomía, según recogen el cine y las series de televisión, no solo llegó a producirse entre comunismo y capitalismo, sino que afectaba también a la propia identidad territorial, no siempre consciente de pertenecer a la Europa central o al bloque del Este ${ }^{1}$. Ni siquiera los espías británicos en The Sleepers, Gerald Lloyd y Susanne Clayton, parecen seguros de ello en algunos de los diálogos. Se han ocupado de este conflicto, tras el cambio político de 1989, Urbonaitè-Barkauskienè (2003) y Dudková

1. Similar tensión está presente también en otros referentes cinematográficos ambientados en momentos históricos de la Checoslovaquia socialista anteriores a la Revolución de Terciopelo, entre ellos títulos tan conocidos como La confesión (L'Aveu, Costa-Gavras, 1970) -sobre el proceso a los disidentes del Partido Comunista checoslovaco en 1952- y la célebre adaptación de La insoportable levedad del ser (The unbearable lightness of being, Philip Kaufman, 1987), que tenía lugar durante la Primavera de Praga de 1968. 
\& Mišíková (2016). Además de este conflicto desde un punto de vista territorial, autores como M. Brzezińska (Universidad de Varsovia) lo han planteado en clave generacional, mostrando, a través de ejemplos como la comedia Identity Card (Občanský průkaz, Ondřej Trojan, 2010-2011), que acontece en 1974-1977, el contraste entre la mirada abierta de los jóvenes frente a la rigidez de sus padres, educados en el sistema implantado en el país en 1948. Caso similar es el de la película Báječná léta pod psa (Petr Nikolaev, 1997), adaptación de una novela de Michal Viewegh acerca de los aspectos más ridículos de la burocracia estatal desde los ojos de un niño. Fuera de la problemática política, es de destacar así mismo la danesa Prag (Ole Christian Madsen, 2006), protagonizada por Mads Mikkelsen (Brzezińska, 2013)².

\section{La disolución de la Praga anterior al régimen socialista}

Estrenada en 2019, en los antecedentes del XXX aniversario de la Revolución de Terciopelo -los dos primeros episodios fueron presentados en realidad en el festival de Karlovy Vary, a comienzos del verano de 2019; posteriormente, el estreno internacional se produjo en septiembre de ese año, dentro de la XLIV edición del Festival Internacional de Cine de Toronto-, The Sleepers es una de las más recientes apuestas del grupo HBO Europa en la República Checa. Se trata de una serie de seis episodios en los que Marie Skálová (la actriz Tatiana Pauhofová), una joven música checa exiliada en Londres junto con su compañero, el activista Viktor Skála (Martin Myšička), regresa a Checoslovaquia tras doce años de exilio. Nada más llegar se produce la desaparición de este último, después de que la pareja sea atropellada por un vehículo que a continuación se da a la fuga.

Los intentos de Marie por reencontrarse con su compañero abrirán una compleja trama en la que participarán tanto la policía política checoslovaca como los espías del MI6 británico y la KGB, todos ellos conscientes de la inminente descomposición del bloque soviético. Los espectadores acompañan a la protagonista por las calles de una Praga que se aparta de lo monumental, desplegando localizaciones

2. Para una aproximación de conjunto al cine checoslovaco, es posible destacar los trabajos de Peter Hames (2004 y 2009). En España, el interés ha ido en aumento desde que José Ángel Ezcurra, director de la revista Nuestro Cine, le dedicase atención al fenómeno del Nuevo Cine Checo (Nová Vina) a mediados de los años sesenta, asunto así mismo abordado por Hames y, muy recientemente, por Gómez Lucas (2020). 
en las que recrear bares clandestinos, destartalados apartamentos con micrófonos ocultos y las oficinas de la ŠtB. Esta disolución de la monumentalidad se muestra ya en el primer episodio de la serie, cuando se produce el regreso de la pareja a la ciudad. Marie y Viktor contemplan durante la noche, alojados en un impersonal edificio del barrio de Holešovice, uno de los grandes templos de la ciudad, aunque de manera lateral y en plena noche, precedido por convencionales tejados y antenas.

Este barrio, Holešovice, situado en un meandro del río Moldava, dentro del distrito de Praga 7, concentra varias de las localizaciones residenciales de la serie, especialmente en las proximidades de la plaza Strossmayer (Strossmayerovo náměstí), así denominada en honor al obispo de origen croata Josip Juraj Strossmayer (1815-1905). Es en estas calles donde se encuentran los domicilios de Alexandra Šliková -la antigua amante de Viktor Skála, cuyo cadáver aparece ahorcado- y de la agregada británica Susanne Clayton (la actriz Hattie Morahan). Son edificios racionalistas, como los bloques de apartamentos de los arquitectos Julius Landsmann y Martin Reiner (1936-1937), construidos en la esquina de Farského a Podplukovník Sochora. No aparece en la serie, sin embargo, el gran referente racionalista del barrio, el destacable Palacio de Exposiciones (Veletržní Palác) de los arquitectos Josef Fuchs y Oldřich Tyl, obra de 1925-1928 y en la actualidad una de las sedes de la Galería Nacional checa3.

Buena parte de la semántica de la serie se transmite por medio de vistas aéreas, como las del Hotel International (František Jeřábek, 1952-1957), uno de los mejores exponentes de la arquitectura socialista checoslovaca (F1). Pese a ser concebido originariamente como hotel, este inmueble de contundente fisonomía soviética se convierte aquí en sede de la ŠtB. Su gran aguja se encuentra rematada por una estrella de cinco puntas que, hasta el año 1989, se iluminaba de color rojo (y que desde la compra del complejo por Holiday Inn refulge en verde, color corporativo de esta cadena de establecimientos).

3. Sobre la arquitectura checa de la primera mitad del siglo XX, a modo de síntesis, es posible destacar los trabajos de Švácha (1985) y Svobodová (2016), así como, en clave más divulgativa, Kohout, Templ \& Šlapeta (1999). No abunda la bibliografía en español, destacando Anděl \& Alborch (1993). 


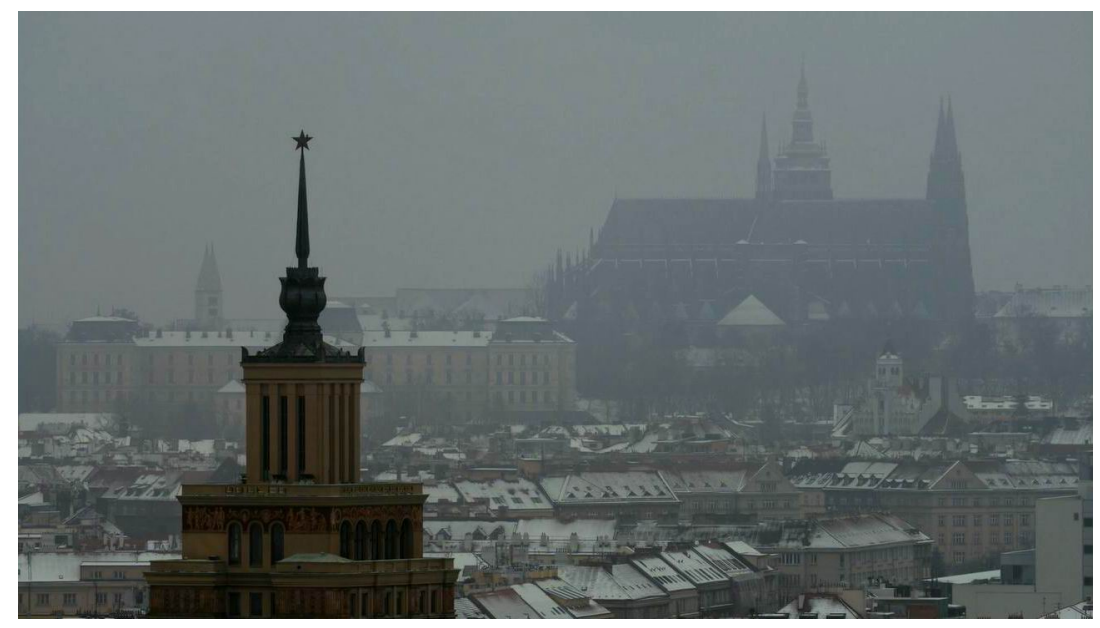

F1. Remate del Hotel International (F. Jeřábek, 1952-1957), ejemplo de rascacielismo socialista, empleado en los exteriores de la serie como sede de la policía política checoslovaca. (C) HBO

El distintivo reluce lúgubremente en varias ocasiones a lo largo del desarrollo de la trama, como si ejerciera una opresiva pulsión sobre los destinos de los personajes. Su primera aparición, de hecho, se produce tras el encuentro sexual entre el mayor Jan Berg (Martin Hofmann) y la secretaria de la ŠtB, Miluska (Kristýna Podzimková). Ambos, desnudos, contemplan desde una ventana el Hotel International, envuelto en bruma. Por el contrario, ya bien avanzada la serie, cuando el comunismo ha caído y Miluska inicia una relación amorosa con un viceministro de la nueva República Checa (el actor Petr Lnenicka), el edificio se manifiesta ya en pleno día. Este sencillo, pero evidente juego de planos nocturnos y diurnos entre estos últimos, es posible destacar las vistas tomadas desde el pabellón Hanavský, edificio neobarroco de finales del siglo XIX situado en el parque Letná, desde donde se disfrutan algunas de las vistas más impresionantes del río Moldava- se va sucediendo paulatinamente, conforme el nuevo país va despertando, amaneciendo más allá del oscuro pasado comunista.

$\mathrm{Ni}$ siquiera los parques se libran de esta opresiva mirada. Los jardines Chotek (Chotkovy sady) -ejemplo de jardín inglés de origen decimonónico (fueron creados en 1832)-, que visita la pareja protagonista en un flashback de sus años de juventud a finales de los setenta, se convierten en un espacio vigilado por agentes de policía de incógnito, entregados a la falsa cotidianidad de dar de comer a las palomas.

Tanto las oficinas como las residencias de los empleados de la policía política contrastan con la prestancia soviética del Hotel International, si bien las primeras fueron filmadas en el interior de un inmueble estrechamente vinculado al pasado 
socialista checo, el edificio Dům Radost (1932-1934), obra de los arquitectos Karel Honzík y Josef Havlíček, bajo la influencia de Le Corbusier. Este gran complejo de oficinas, en su momento el edificio más alto de Praga, ha sido empleado como sede sindical desde comienzos de los años cincuenta. Es allí donde fueron recreados el despacho de la secretaria Miluska y los archivos de la ŠtB. Sin embargo, al igual que sucedía con los bloques de Holešovice, The Sleepers no enfatiza la gran aportación checa a la arquitectura de la Modernidad. Por el contrario, los gastados suelos de linóleo e interiores chapados de madera barata transmiten la misma sensación de polvorienta decadencia.

Tampoco escapan a esta consideración las viviendas de los policías, pequeñas, oscuras, impregnadas de cierta sordidez. El mayor Berg habita un apartamento para funcionarios, donde recibe, no sin preocupación, las visitas de su amante (la localización exacta es un edificio del barrio de Břevnov, en la zona occidental de Praga, en las proximidades del Hospital Militar). Su superior, el coronel Václav Vlach (Jan Vlasák), convive con su esposa enferma en un pequeño chalet. Allí, el veterano agente del estalinismo acostumbrado a quebrar el ánimo de los disidentes se desvive por alimentar los peces de su acuario, envuelto en una mortecina luz verde.

Por el contrario, la casa del padre de la protagonista, un anciano opositor al régimen socialista mostrado en flashback en la década de los setenta, es presentada en la serie como un acogedor espacio repleto de libros y música, cuyo portal es una pequeña pero elegante portada art decó -flanqueada por dos pequeñas estatuas de búhos- en la calle Podskalská (Nové Město). La música, oficio de la protagonista de la serie -en un guiño, quizás, al violonchelista interpretado por Zdenek Sverák en Kolja, también en los albores de la Revolución de Terciopelo- es representada sin atisbo alguno de decadencia pese a estar sometida también al aparato burocrático del Estado, como el resto de la sociedad checoslovaca. Son responsables de esta monumentalidad interiores como la Nová Scéna -la sala londinense donde Marie ofrece un concierto- y la sala Dvořák del Rudolfinum de Praga, donde la joven oposita a una plaza en la Filarmónica checoslovaca en 1977, según es mostrado en flashback. Este último edificio, obra de los arquitectos Jo- 
sef Zítek y Josef Schulz, transmite una gran escala a través de la columnata interior del espacio musical; no en vano, fue sede parlamentaria entre los años 1919 y 1939.

Tras la caída del comunismo, la residencia oficial del nuevo líder checo y su esposa es un elegante espacio situado en el barrio burgués de Střešovice, al oeste de la ciudad, en el distrito de Praga 6 (donde, por cierto, se encuentra la Villa Müller, de Adolf Loos). La sede del nuevo Gobierno, que en la República Checa actual es la Academia Straka -edificio neobarroco construido en la última década del siglo XIX, bajo los diseños de Václav Roštlapil (1856-1931)-, es en The Sleepers la sede del Ministerio de Transporte. Se trata del antiguo Ministerio de Ferrocarriles checoslovaco, construido entre 1929 y 1932, obra del arquitecto, urbanista e ingeniero Antonín Engel (1879-1958).

Otra sede ministerial, la de Industria y Comercio, enorme complejo construido a orillas del río Moldava por el arquitecto Josef Fanta (1856-1954) entre 1928 y 1934, el cual albergó la sede del Comité Central del Partido Comunista, es la Embajada británica (F2). Concretamente, el acceso de los diplomáticos se produce a través de la Oficina de Patentes, una suerte de edículo de planta oval con entablamento dórico, sustentado por pares de medias columnas anilladas, situado en la intersección de las calles Rásnovka y Hradební. A diferencia de los interiores de la policía política checoslovaca, los de este edificio, filmados en el interior del palacio Petschek (Petschkův Palác), ejemplo de arquitectura bancaria de los años veinte, son mucho más prestantes.

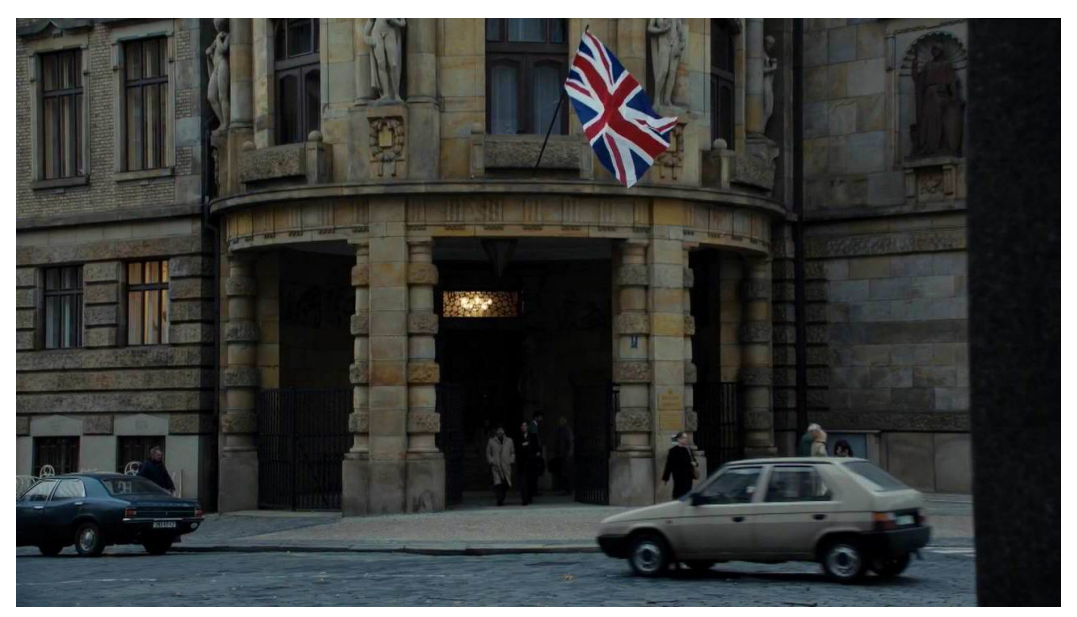

F2. La embajada británica es en realidad la sede del Ministerio de Industria y Comercio, construido por Josef Fanta entre 1928 y 1934. (C) HBO 


\section{Hospitales, infraestructuras y otras localizaciones}

No es nuestra intención incluir aquí una relación detallada del resto de localizaciones. Mencionaremos, sin embargo, algunos edificios de especial interés para el desarrollo de la trama, comenzando por varios hospitales. Uno de estos espacios, donde Marie acaba ingresada tras sufrir el atropello, es el exterior de la Clínica de Urología de la Universidad Carolina de Praga (VFN Urologická klinika, ejemplo de arquitectura brutalista de los arquitectos Vratislav Růžička y Boris Rákosník, 1971-1976), en la calle Ke Karlovu, 6 (distrito de Praga 2). Otra de estas localizaciones sanitarias, donde permanece ingresada la esposa del coronel, Vlasta Vlachová (Lucie Juricková), es el centro médico Thomayer (Thomayerova Nemocnice), en el distrito de Praga 4. El hospital psiquiátrico donde Marie acaba ingresada, con su amplio jardín, fue recreado en uno de los grandes edificios residenciales de Bohnice (distrito de Praga 8), al norte de la ciudad. No fue aprovechado para tal fin -sin duda, con el afán ya mencionado de diluir las arquitecturas pintorescas de la ciudad- el magnífico sanatorio de estilo Sezession construido en las inmediaciones en 1909 por el arquitecto Václav Roštlapil.

Los servicios de Urgencias y ambulancias fueron filmados en un complejo clínico del barrio de Ciudad Nueva (Nové Město), en Malá Štěpánská 4, junto al parque de Carlos (Karlovo Náměstí). También fueron aprovechados para este fin los exteriores de la Unión Deportiva Checa (Česká unie sportu), junto al inmenso complejo deportivo Strahov, en el distrito de Břevnov (F.3). La tribuna occidental, construida entre 1932 y 1938, según los diseños de Ferdinand Balcárek y Karel Kopp, es un ejemplo más de magnífica arquitectura racionalista.

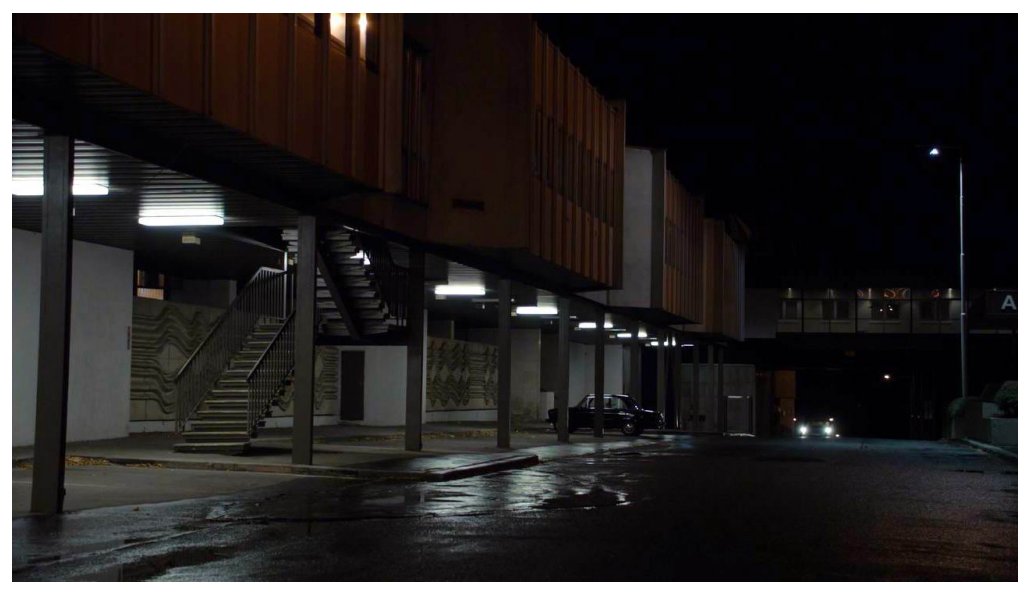

F3. Exteriores de la Unión Deportiva Checa (Česká unie sportu), junto al inmenso complejo deportivo Strahov, en el distrito de Břevnov. (C) HBO 
Los desplazamientos en tren, aunque merecedores de atención dentro de la trama, no poseen excesivo interés. Transcurren en andenes de estaciones como las de Smíchov y Masaryk, ambas en Praga. La estación de Kralupy nad Vltavou, no muy lejos de la capital, es empleada también en varias ocasiones, aunque no como escenario ferroviario, sino como zona de paso o como bar. También aparece en la serie el depósito de trenes de Lužná u Rakovníka (línea Praga-Chomutov), el cual inició su andadura en una fecha tan temprana como 1863. Mayor interés posee el espacio empleado para recrear los interiores del aeropuerto de Ruzyně: los responsables de la serie utilizaron el Palacio de Congresos de Nusle (Praga 4), inmenso complejo construido por el ingeniero y arquitecto Vladimír Conk entre 1976 y 1981.

Fuera de la ciudad de Praga, destacaremos también algunas localizaciones; entre ellas, la plaza Pod Branou de Liberec, en el norte del país, muy cerca de Polonia y Alemania. Allí se encuentra la tienda de comestibles a la que acude el agente británico Gerald Lloyd (David Nykl) durante el secuestro de Victor Skalá. Dicho comercio es en realidad parte del complejo industrial construido para los empleados de la familia Liebieg entre 1911 y 1923. Con respecto al escondite de Skalá, situado supuestamente en la República Federal Alemana, se encuentra dentro de una empresa llamada Juttex (la cual debería ser en realidad «Juta», la mayor compañía textil checa en la realidad, en una de cuyas instalaciones, en Višňová, al sur del país, no lejos de la frontera con Austria, avanza la trama). Con respecto a la base soviética en territorio checoslovaco, es recreada con los símbolos de la URSS en la antigua base de misiles de Klondajk, en la boscosa zona de Brdy, al suroeste de Praga, muy cerca de la ciudad de Dobříšs. El búnker donde se producen los interrogatorios, por otra parte, fue filmado en parte del complejo museístico militar de Mordové Rokle, en Lipník.

Hemos dejado para el final dos inmuebles de especial interés: la sede del Sokol y el Krematorium Strašnice, ambos en Praga. El primero de ambos fue construido en el borde sur de los jardines Rieger (Riegrovy sady), dentro del barrio residencial de Vinohrady, por los arquitectos František Marek, Václav Vejrych y Jaroslav Kabeš, tras el concurso convocado en 1936 (Platovská, 2011). Pese a sus azarosos primeros años -fue ampliado durante la ocupación nazi, para convertirse des- 
pués en hospital militar y centro de repatriación-, es necesario destacar su naturaleza eminentemente deportiva, ya que fue concebido para albergar la sede del Sokol de Praga. Esta organización gimnástica, creada en 1862 y con fuerte arraigo nacionalista en los territorios del antiguo Imperio Austrohúngaro, acabaría prohibida por los comunistas checos en 1948 (Esparza, 2012); curiosamente, en The Sleepers este edificio permite ambientar el acceso al pub frecuentado por los jóvenes disidentes, con su característica línea de pilares-pantalla, que ofrecen a la fachada principal un interesante juego de luces y sombras ( $\left.\mathrm{F}_{4}\right)\left(\mathrm{F}_{5}\right)$.
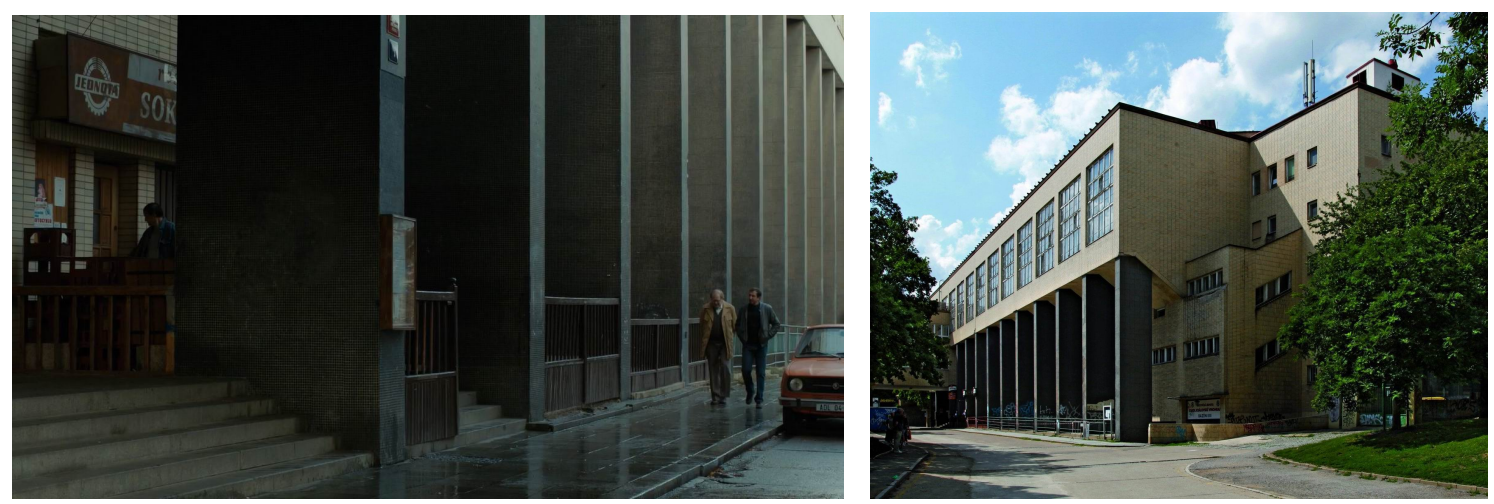

F4. El mayor Berg (Martin Hofmann) y el coronel Vlach (Jan Vlasák) frente a los pilares-pantalla de la sede del Sokol de Vinohrady. (C) HBO

F5. Sede del Sokol (František Marek, Václav Vejrych y Jaroslav Kabeš). Encyklopedie Prahy 2

El Krematorium Strašnice, obra de Alois Mezera (1889-1945), construido entre 1929 y 1932 en la zona oriental del cementerio de Vinohrady, es otro de los complejos arquitectónicos más notables de cuantos aparecen en la serie. Se trata del espacio donde el coronel Vlach se despide de los restos mortales de su esposa y supone un nuevo guiño a Kolya, ya que es en este lugar donde se veía obligado a trabajar el viejo violonchelista (F6) (F7). El edificio, resultado de un concurso convocado en 1926, al que concurrieron cuarenta proyectos sometidos al juicio de un jurado con figuras como Antonín Engel y Oldřich Tyl, fue finalmente obra de Mezera, cuya propuesta era radicalmente distinta en comparación con otras semejantes, como el crematorio del cementerio de Olšany, planteado por František Xaver Nevole en estilo neorrenacentista a comienzos de la década de los años veinte. El certamen trajo consigo un interesante debate acerca de las características formales, la tipología y función arquitectónicas, en buena medida trasladado a las páginas de la revista Stavba, una de las principales herramientas de difusión del pensamiento arquitectónico racionalista en Europa Central en época de entreguerras. 

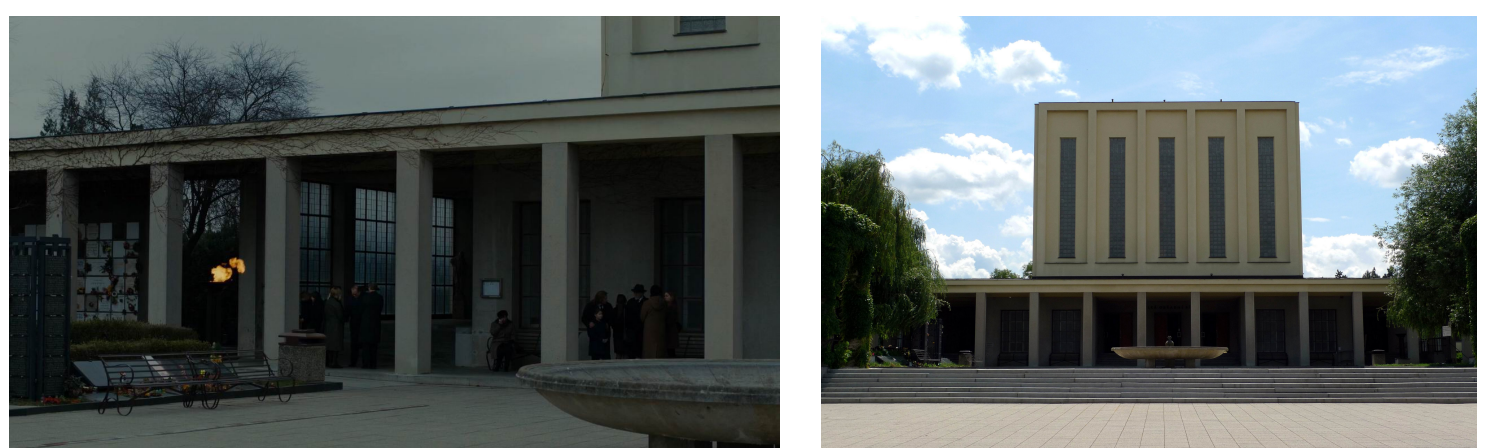

F6. Frente porticado del Krematorium Strašnice, localización habitual en otras producciones checas. (C) HBO

F7. Krematorium Strašnice (1929-1932), del arquitecto Alois Mezera. Creative Commons

Otra revista de la época, Krematorium, recoge los pasos previos a la construcción y su desarrollo, cuyas láminas están disponibles en el blog Czumalova nástěnka. El resultado es un complejo de grandes dimensiones -el Krematorium Strašnice es considerado el crematorio más grande de Europa-, donde el volumen del salón ceremonial, iluminado por cinco altos huecos cerrados con ladrillos de vidrio, se impone sobre un regular propileo que manifiesta semejanzas con referentes del Racionalismo europeo como el arquitecto italiano Adalberto Libera. Posee la consideración de monumento cultural desde 1958.

\section{Conclusión}

Según hemos tenido la ocasión de apreciar, The Sleepers se vale de algunos interesantes ejemplos de arquitectura checoslovaca de la primera mitad del siglo XX para recrear su particular interpretación del ocaso comunista. En su afán por diluir la Praga más monumental y explotada desde el punto de vista cinematográfico, la serie de Ivan Zachariáš para HBO abandona la Ciudad Vieja (Staré Město) -espacio recurrente en la mayor parte de ambientaciones históricas filmadas en la capital checa, como pudiera ser Kafka (Steven Soderbergh, 1991), entre otras muchas- con el fin de ambientar en zonas muy distintas, como el barrio de Holešovice, el periodo inmediatamente anterior a la Revolución de Terciopelo. The Sleepers no acontece en medio de la monumentalidad barroca de esta antigua ciudad, sino entre edificios residenciales, hospitales y complejos diplomáticos. La representación del ominoso pasado político que Ivan Zachariáš despliega a través de la arquitectura está especialmente presente en la identificación del rascacielismo socialista -el Hotel International (1952-1957), de F. Jeřábek- con el apa- 
rato policial. Paradójicamente, el edificio que en The Sleepers es sede de la sórdida y cruel ŠtB checoslovaca, permanentemente envuelto en luz mortecina hasta producirse la caída del régimen, es en la actualidad propiedad de una cadena hotelera estadounidense.

Frente a otras producciones escasamente afines al pasado comunista checoslovaco después de la Primavera de Praga -la más temprana y contundente probablemente sea La confesión; las más conocidas internacionalmente, La insoportable levedad del ser y Kolja-, la serie de Ivan Zachariáš destaca por su magnífica elección de localizaciones. Entre ellas, es posible señalar algunos grandes ejemplos de arquitectura contemporánea, como el racionalista Krematorium Strašnice (1929-1932), obra de Alois Mezera, que también aparecía en Kolja para subrayar el inminente final de un sistema político en descomposición.

El director de la serie, que acababa de ofrecer un magnífico aunque inmisericorde fresco de la Checoslovaquia rural en Wasteland (Pustina, 2016) -un crudo relato sobre la desaparición de una menor y la especulación industrial en una cuenca minera, sin el menor asomo de indulgencia hacia el lugar y sus habitantes-, volvió en The Sleepers a valerse de los entornos y de sus arquitecturas, deprimidas, grises, permanentemente envueltas en una mortecina atmósfera, para presentar a un conjunto de personajes con escasas esperanzas. Escasos años atrás, Agnieszka Holland había ofrecido algo semejante en Burning Bush, cuyos tres episodios sobre la autoinmolación del estudiante Jan Palach en 1968 y el proceso posterior concentraban eficazmente, sobre todo en interiores, la angustia de sus protagonistas.

The Sleepers, en este sentido, contribuye también con su elección de espacios a la construcción simbólica del postcomunismo checo, en la línea de los estudios desarrollados por investigadoras como Marta Brzezińska, Veronika Pehe o, más recientemente, en el ámbito de la representación del estalinismo en las series de televisión de la Rusia postsoviética, Viktoriya Sukovata.

\section{Referencias bibliográficas}

Anděl, J. \& Alborch, C. (1993). El Arte de la Vanguardia en Checoslovaquia 19181938. Valencia: Ivam. 
Barra, L. \& Scaglioni, M. (eds.) (2020). A European television fiction renaissance: Premium production models and transnational circulation. Routlege.

Block, M. (2013). World Film Locations: Prague. Bristol: Intellect Ltd.

Brzezińska, M. (2013). Youth, Communism and the Cinema-Ways of Depicting the Past in Selected German, Polish and Czech Films Produced after 1989. Palimpsest: Czasopismo Socjologiczne, 5, 17-24.

Camarero, G. (2013). Ciudades europeas en el cine. Madrid: Akal.

Dudková, J. \& Mišíková, K. (2016). Transformation Processes in Post-Socialist Screen Media. Bratislava: Academy of Performing Arts.

Esparza, D. (2012). Miroslav Tyrš y el Sokol. International Journal of Sport Science, VIII, 27, 103-112.

Gómez Lucas, C. (2020). El nuevo cine checo. Revolución cinematográfica en los '6o. Valencia: Shangrila Ediciones.

Hames, P. (2004). Cinema of Central Europe. Londres: Wallflower Press.

Hames, P. (2009). Czech and Slovak Cinema: Theme and Tradition. Edimburgo: Edinburgh University Press.

Hejlícková, I. (1989). Los estudios Barrandov. 55 años de historia del cine checo. Valladolid: Semana Internacional de Cine.

Kohout, M., Templ, S. \& Šlapeta, V. (1999). Prague 2oth Century Architecture. Springer.

Pehe, V. (2015). The colours of socialism: visual nostalgia and retro aesthetics in Czech film and television. Canadian Slavonic Papers, 57, 3-4, 239-253.

Pehe, V. (2020). Velvet Retro: Postsocialist Nostalgia and the Politics of Heroism in Czech Popular Culture. Nueva York: Berghahn Books.

Platovská, M. (2011). Slavné stavby Prahy. Foibos Books.

Sukovata, V. (2021). The Stalinist Past in Contemporary Russian TV Serials: Reconfigurations of Memory. Journal of Nationalism Memory \& Language Politics, 15(1), 69-86.

Svobodová, M. (2013). Krematorium v procesu sekularizace českých zemí 20. století: ideové, stavební a typologické proměny. Praga: Artefactum.

Svobodová, M. (2016). Bauhaus a Československo 1919-1938: studenti, koncepty, kontakty. KANT.

Švácha, R. (1985). Od moderny $k$ funkcionalismu: proměny pražské architektury první poloviny dvacátého století. Odeon.

Urbonaité-Barkauskiené, V. (2003). Cinematic Representations of Post-Socialist East Central Europe in Western Feature Films (or, 'Dear Sweet Mother of God-we're in Eastern Europe!'). East / West: The Scholarly Journal for History and Culture, 16-17, 447-459.

\section{Páginas web}

Blog Czumalova nástěnka. Recuperado de $\underline{\text { https://czu- }}$ malo.wordpress.com/2016/12/04/u3v-fsv-cvut-pamatky-velke-prahy-prednaska-6-prosince-2016/ 